\title{
The In Vitro Effects of Granulocyte and Granulocyte-Macrophage Colony-Stimulating Factor on Interleukin-3-Dependent Proliferation of Human Neonatal Circulating Progenitor Cells
}

\author{
ALISON R. BEDFORD RUSSELL, E. GRAHAM DAVIES, FRANCES M. GIBSON, AND \\ EDWARD C. GORDON-SMITH
}

Departments of Child Health [A.R.B.R., E.G.D.] and Haematology[F.M.G., E.C.G.-S.], St George's Hospital Medical School, Cranmer Terrace, London SW17 ORE, United Kingdom

\begin{abstract}
AVS
Recombinant human granulocyte (rhG) colony-stimulating
factor (CSF) and recombinant human granulocyte-macrophage (rhGM) CSF have been used to enhance neonatal neutrophil host defense. We aimed to determine the comparative efficacy of rhG-CSF and rhGM-CSF in increasing numbers of granuloctye colony-forming unit (CFU-G) and granulocyte-macrophage colony-forming unit (CFU-GM) in recombinant human (rh) IL-3dependent cultures of human neonatal circulating hematopoietic progenitor cells, including cells from infants born to hypertensive mothers. We also investigated the relationship between fractional increase in CFU-G and endogenous plasma concentraton of G-CSF. Circulating mononuclear cells were harvested from 25 neonates, and standard short-term assays in semisolid agar were established in the presence of rhIL-3 alone, rhIL-3 with rhG-CSF and rhGM-CSF, and both rhG-CSF and rhGM-CSF. CFU-G and CFU-GM were counted on d 14. Total colony number and CFU-G were significantly greater in cultures supplemented with rhG-CSF, with or without rhGM-CSF ( $p<0.001$ and $p<$ 0.0005 for total colony number and CFU-G, respectively), when compared with cultures with rhIL-3 alone. Progenitor cells from three infants born to hypertensive mothers responded similarly. Total colony numbers and CFU-G were not increased by rhGMCSF alone or by addition of rhGM-CSF to rhG-CSF; however,
\end{abstract}

the proportions of CFU-GM were $(p<0.05$ and $p<0.001$, respectively, compared with rhIL-3 alone). Fractional increases in CFU-G with rhG-CSF were independent of plasma concentraton of G-CSF $(r=0.17 ; 95 \%$ confidence interval -0.5 to $0.19 ; p=0.35$ ). rhG-CSF was more efficacious than rhGM-CSF in enhancing CFU-G numbers in rhIL-3-dependent cultures, and plasma concentration of G-CSF did not predict response. (Pediatr Res 37: 630-633, 1995)
Abbreviations
G-CSF, granulocyte colony-stimulating factor
GM-CSF, granulocyte-macrophage colony-stimulating factor rhG-CSF, recombinant human granulocyte colony-stimulating factor
rhGM-CSF, recombinant human granulocyte-macrophage colony-stimulating factor
[G-CSF], granulocyte colony-stimulating factor concentrations
rhIL-3, recombinant human IL-3
CFU-G, granulocyte colony-forming unit
CFU-GM, granulocyte-macrophage colony-forming unit
PIH, pregnancy-induced hypertension
IMDM, Iscove's modification of Dulbecco's medium

Neutropenia occurs in up to $35 \%$ of babies admitted to the neonatal intensive care unit and is more likely in preterm infants, those with birth weights of less than $2000 \mathrm{~g}$, and in multiple gestation pregnancies (1). Neutropenia is also a particularly frequent finding in babies born to mothers with PIH, exposing them to an increased risk of sepsis (2). The combination of neutropenia and sepsis results in a neonatal mortality rate of up to $60 \%$ (1). Efforts have therefore been directed at

Received October 26, 1993; accepted November 28, 1994

Correspondence: Dr. A. R. Bedford Russell, Department of Child Health, Lanesborough Wing, St George's Hospital Medical School, Cranmer Terrace, London SW17 0RE, UK

Supported by Action Research (A.R.B.R.). enhancing neonatal neutrophil host defense. The hematopoietic growth factors G-CSF and GM-CSF have been used in the management of neutropenia secondary to various conditions (3). G-CSF acts on committed precursor cells to produce mature neutrophils, but may also have an effect on earlier progenitor cells when in combination with IL-3 $(4,5)$. In animal models rhG-CSF has been shown to increase the circulating neutrophil number, neutrophil storage pool, and bone marrow progenitor pool and improve survival from group B Streptococcus infection when administered in combination with antibiotics $(6,7)$. The former has also been shown for human neonates treated with rhG-CSF (8). GM-CSF acts on multipotential, erythroid, and eosinophilic hematopoietic pro- 
genitor cells and has activities overlapping with but distinct from IL-3 (9-11). In clinical studies in adults rhGM-CSF given on an equal-mass basis does not increase neutrophil levels as much as rhG-CSF and results in a monocytosis and eosinophilia (3). Given in combination with antibiotics to neonatal rats infected with group B streptococcus, rhGM-CSF has been shown to decrease mortality rates (12). Thus both rhG-CSF and rhGM-CSF could potentially be used to enhance human neonatal neutrophil numbers and therefore augment neonatal host defense mechanisms. However, the comparative effects of rhG-CSF and rhGM-CSF on isolated human neonatal circulating progenitor cells has not previously been studied.

Neonates have an easily accessible, plentiful supply of circulating progenitor cells (13), more abundant than found in adults (14). This study was designed primarily to quantitatively compare the effects of rhG-CSF and rhGM-CSF on human neonatal circulating progenitor cells, in an rhIL-3-dependent culture system and to establish which CSF would most effectively increase the number of neutrophilic cells, as measured by CFU-G production. Second, we aimed to investigate whether rhG-CSF and rhGM-CSF would affect progenitor cells from babies born to mothers with PIH, in a similar way to those from babies with normotensive mothers. Last we aimed to investigate whether or not the response to rhG-CSF correlated with endogenous plasma [G-CSF]. It has been proposed that neonatal neutropenia may be secondary to deficient production of endogenous G-CSF during activated states (15). If this were the case we postulated that progenitor cells from neonates with low endogenous plasma [G-CSF] may be more responsive to exogenous rhG-CSF than cells from those with high endogenous plasma [G-CSF].

Patients and methods. Blood $(0.5-1 \mathrm{~mL})$ was collected from 25 newborn babies admitted to the regional tertiary neonatal unit with the first routine blood sampling (at $0-2 \mathrm{~h}$ of life) into sterile tubes with preservative-free heparin ( $5 \mu \mathrm{L}$ containing 25 IU). Median gestational age was $32 \mathrm{wk}$ (range $24-41 \mathrm{wk}$ ) and median birth weight was $1.70 \mathrm{~kg}$ (range $0.67-3.80 \mathrm{~kg}$ ); three infants were born to mothers with $\mathrm{PIH}$, diagnosed by previously defined criteria (2). Further samples were obtained from three infants at $2 \mathrm{wk}$ of age for repeat studies. Plasma was isolated after centrifugation ( $400 \times g$ for $10 \mathrm{~min}$ ) and stored at $-20^{\circ} \mathrm{C}$ until [G-CSF] were estimated in duplicate using a commercial ELISA (British Biotechnology Products Ltd, Oxon OX14 3YS). The cells were resuspended in IMDM (GIBCO, UK) (containing $102 \mathrm{U}$ penicillin and $100 \mu \mathrm{g} / \mathrm{mL}$ streptomycin), supplemented with $10 \%$ heat-inactivated FCS (ICN Flow, $\mathrm{UK}$ ), and centrifuged on Ficoll-Hypaque ( $400 \times g$ for $25 \mathrm{~min}$ ). The mononuclear fraction was isolated, washed twice in IMDM, and resuspended in IMDM with $10 \%$ FCS for counting. Progenitor cell responses to rhG-CSF and rhGM-CSF were assayed using a standard method. Briefly, $0.5 \times 10^{5}$ mononuclear cells were added to $1 \mathrm{~mL}$ IMDM in $35-\mathrm{mm}$ dishes in duplicate supplemented with: $0.9 \%$ methylcellulose (Terry Fox Labs, Vancouver), $2 \mathrm{mM}$ L-glutamine, $30 \%$ FCS, $1 \% \mathrm{BSA}, 7.5 \% \mathrm{NaHCO}_{3}$, and $10^{-4} \mathrm{M} p$-mercaptoethanol. Cell cultures from each infant were supplemented with the following combinations of recombinant growth factors, before incubating at $37^{\circ} \mathrm{C}$ in $5 \% \mathrm{CO}_{2} / 95 \%$ air: $50 \mathrm{ng} / \mathrm{mL}$ rhIL-3 (sp act,
$8.8 \times 10^{6} \mathrm{U} / \mathrm{mg}$; Escherichia coli-derived recombinant human aglycosylated; Sandoz Pharma); $50 \mathrm{ng} / \mathrm{mL}$ rhIL-3 with 50 $\mathrm{ng} / \mathrm{mL}$ rhG-CSF (sp act, $10^{8} \mathrm{U} / \mathrm{mg} ; E$. coli-derived recombinant-methionyl human aglycosylated; Amgen UK); $50 \mathrm{ng} / \mathrm{mL}$ rhIL-3 with $50 \mathrm{ng} / \mathrm{mL}$ rhGM-CSF (sp act, $5.6 \times 10^{6} \mathrm{U} / \mathrm{mg}$; mammalian Chinese hamster ovary-derived recombinant human glycosylated; Sandoz Pharma); and the same doses of rhIL-3 with both rhG-CSF and rhGM-CSF. The doses of each growth factor used were those required for maximum stimulation, determined by previous titration experiments, and used for all cultures. CFU-G and CFU-GM containing more than 40 cells were counted on d 14, using a tissue culture inverted microscope. Morphologic characterization of plucked colonies was confirmed after cytocentrifugation and staining with Wright's stain. Colonies of CFU-G contained precursor and terminally differentiated neutrophils only. CFU-GM were composed of large, foamy macrophages in addition to neutrophilic cells at different stages of differentiation as described above.

Ethical approval for the study was obtained from the local ethics committee.

Statistical analysis of colony culture data were by analysis of variance after $\log$ transformation to normalize the data; the least significant difference test was used to determine significant intergroup differences. The product-moment correlation coefficient was used to determine the relationship between endogenous [G-CSF] and fractional increase in colonies with addition of rhG-CSF to the culture system.

\section{RESULTS}

Total colony numbers (CFU-G + CFU-GM) were significantly increased in rhG-CSF $(p<0.001)$ and rhG-CSF/rhGMCSF-supplemented cultures $(p<0.0005)$, but not in cultures supplemented with rhGM-CSF only ( $p>0.05$ ), when compared with those with rhIL-3 alone, suggesting that rhIL-3 and rhG-CSF, but not rhGM-CSF, are synergistic (Fig. 1). This increase was accounted for by a significantly greater number of CFU-G with rhG-CSF supplementation $(p<0.005)$ and additionally in rhG-CSF/rhGM-CSF-supplemented cultures of CFU-GM ( $p<0.001$ ) (Figs. 2 and 3); CFU-G were not significantly greater in cultures supplemented with rhGM-CSF alone ( $p>0.05)$ (Fig. 2). Although total CFU-G + CFU-GM were not increased in rhGM-CSF-supplemented cultures, the proportion of CFU-GM was $(p<0.05)$; CFU-GM were not increased with rhG-CSF supplementation ( $p>0.05$ ) (Fig. 3). Comparing the actions of rhG-CSF and rhGM-CSF in IL-3-

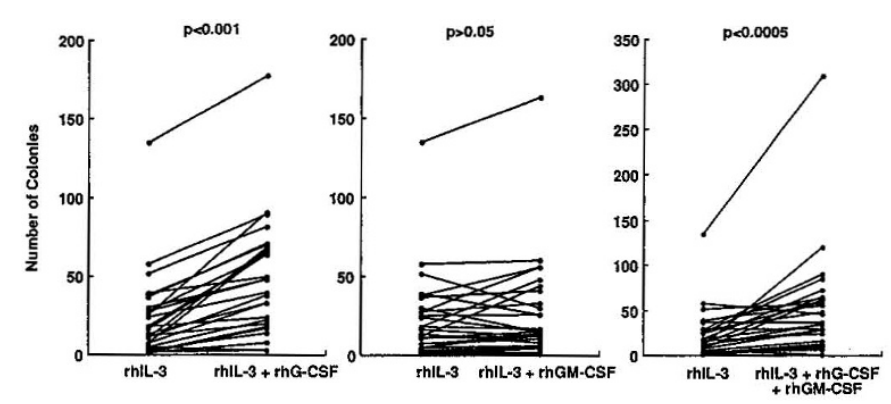

Figure 1. Total colony numbers (CFU-G + CFU-GM) with the various combinations of growth factors. 

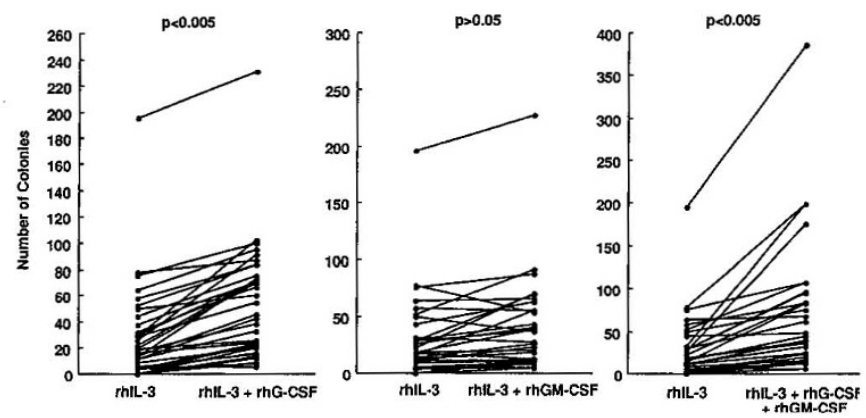

Figure 2. CFU-G only with the various combinations of growth factors.

supplemented cultures (direct comparisons not displayed graphically), the use of rhGM-CSF with rhG-CSF did not increase the total colony number, or the number of CFU-G, when compared with using rhG-CSF alone with rhIL-3 (median [range] $=55[6-386]$ versus $64[6-231]$ for total colony number and 36 [1-310] versus 44 [3-178] for CFU-G only; $p$ $>0.05$ ), suggesting that these two cytokines are not synergistic in this culture system. rhG-CSF induced significantly greater numbers of CFU-G than did rhGM-CSF (44 [3-178] versus 15 [1-163]; $p<0.01)$, but total colony numbers were not significantly different $(64[6-231]$ versus $38[5-228] ; p>0.05)$. Sufficient progenitor cells were isolated from only five newborn babies to enable culture with rhG-CSF and rhGM-CSF alone. No colonies were developed in any culture in the absence of rhIL-3.

The individual responses of the infants born to mothers with $\mathrm{PIH}$ and the baby's [G-CSF] and absolute neutrophil counts at the times of cell harvest are shown in Table 1. Reference ranges for absolute neutrophil count are according to Manroe's criteria at $0-2 \mathrm{~h}$ of age (16). The progenitor cell responses of babies born to hypertensive and normotensive mothers were similar.

The response of progenitor cells to rhG-CSF, in terms of fractional increase in number of CFU-G, was independent of endogenous plasma [G-CSF] at the time of cell harvest $(r=$ $-0.17 ; 95 \%$ confidence interval -0.5 to $0.19 ; p=0.35$ ) (Fig. 4).

\section{DISCUSSION}

Our study demonstrates that rhG-CSF enhances the rhIL-3dependent proliferation of human neonatal circulating progenitor cells, and differentiation into neutrophilic cells (CFU-G). Similar responses occur in progenitor cells derived from in-
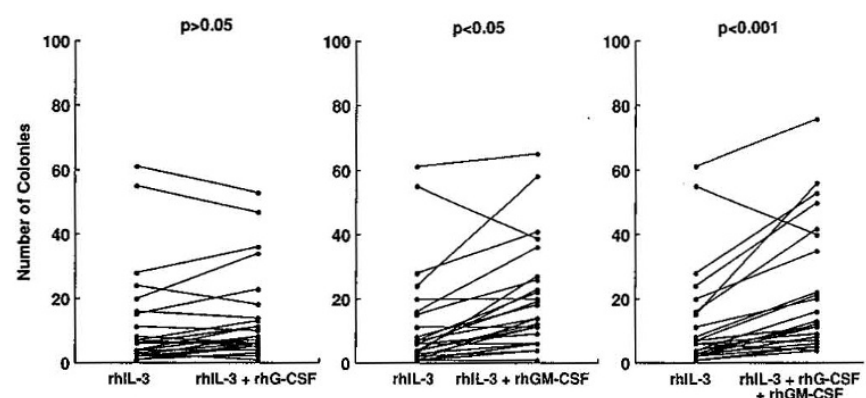

Figure 3. CFU-GM only with the various combinations of growth factors.
Table 1. Total number of cell colonies (CFU-G $+C F U-G M) / 10^{5}$ formed from circulating progenitor cells of infants born to mothers with pregnancy-induced hypertension, in response to the cytokine combinations

\begin{tabular}{|c|c|c|c|c|c|c|}
\hline \multirow[b]{2}{*}{$\begin{array}{c}\text { Patient } \\
\text { no. }\end{array}$} & \multirow[b]{2}{*}{$\begin{array}{c}\text { ANC } \\
\left(\times 10^{9} / \mathrm{L}\right)\end{array}$} & \multirow[b]{2}{*}{$\begin{array}{c}\text { Plasma } \\
{[\mathrm{G}-\mathrm{CSF}]} \\
(\mathrm{pg} / \mathrm{ml})\end{array}$} & \multicolumn{4}{|c|}{ Total no. of cell colonies } \\
\hline & & & IL-3 & $\begin{array}{c}\text { (CFU-G } \\
\text { IL-3/ } \\
\text { G-CSF }\end{array}$ & $\begin{array}{c}\text { CFU-GM) } \\
\text { IL-3/ } \\
\text { GM-CSF }\end{array}$ & $\begin{array}{c}\text { IL-3/ } \\
\text { G-CSF } \\
\text { GM-CSF }\end{array}$ \\
\hline 1 & 3.3 & 52 & $\begin{array}{c}64 \\
(58+8)\end{array}$ & $\begin{array}{c}95 \\
(90+6)\end{array}$ & $\begin{array}{c}66 \\
(60+18)\end{array}$ & $\begin{array}{c}68 \\
(46+22)\end{array}$ \\
\hline 2 & 0.3 & 715 & $\begin{array}{c}9 \\
(3+6)\end{array}$ & $\begin{array}{c}20 \\
(14+6)\end{array}$ & $\begin{array}{c}11 \\
(5+6)\end{array}$ & $\begin{array}{c}16 \\
(9+7)\end{array}$ \\
\hline 3 & 2.5 & 145 & $\begin{array}{c}26 \\
(11+15)\end{array}$ & $\begin{array}{c}91 \\
(68+23)\end{array}$ & $\begin{array}{c}41 \\
(15+26)\end{array}$ & $\begin{array}{c}176 \\
(120+56)\end{array}$ \\
\hline
\end{tabular}

Mean of duplicate cultures shown. ANC $=$ absolute neutrophil count of baby at time of mononuclear cell harvest (normal range ${ }^{16} 1.8-7.2 \times 10^{9} / \mathrm{L}$ ).

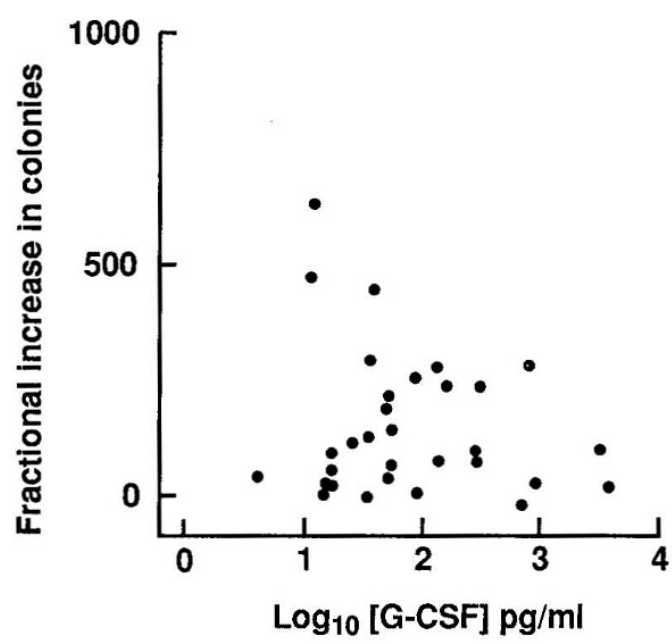

Figure 4. The relationship between plasma $\log _{10}[\mathrm{G}-\mathrm{CSF}]$ and rhG-CSFstimulated CFU-G response ( $r=0.17 ; 95 \%$ confidence interval, -0.5 to 0.19 ; $p=0.35$ ).

fants born to mothers with PIH. These results are consistent with previous reports that rhG-CSF acts synergistically with rhIL-3 $(5,11)$. This effect was not seen with rhGM-CSF and is compatible with previous demonstrations that GM-CSF and IL-3 are not synergistic, but have overlapping activities at early stages of hematopoiesis (9-11). This probably occurs because receptors for GM-CSF and IL-3 share a common $\beta$-subunit resulting in binding cross-competition (17).

We could not demonstrate synergism between rhG-CSF and rhGM-CSF in rhIL-3-dependent cultures. This is not surprising in view of the overlap in activities between IL-3 and GM-CSF. No colony growth occurred when available cells from newborn babies $(n=5)$ were cultured with rhG-CSF or rhGM-CSF in the absence of rhIL-3. Colony growth with the individual growth factors and synergy between rhG-CSF and rhGM-CSF in the absence of rhIL-3 has previously been demonstrated in preparations of highly enriched $\mathrm{CD} 33+$ / CD34+ cells from the bone marrow of normal adult volunteers (18). However, this may be due to structural differences in preterm neonatal, compared with adult, stem cell receptors. Up-regulation of receptor expression may occur only after the early neonatal period, because temporal expression of the $\beta$-subunit has been demonstrated in murine embryonic stem 
cells and early blastocysts $(17,19,20)$. Also significant differences have been found in lymphocyte phenotypes of human infants at birth and at $5 \mathrm{~d}$ of age (21).

The clinical implication of our results is that if cytokine therapy is to be considered for the management of neonatal neutropenia thG-CSF would be the most appropriate choice. This is consistent with the results of a clinical study in older children with severe congenital neutropenia, in which rhG-CSF was more effective than rhGM-CSF at increasing neutrophil count (22). It is probable that no benefit would be conferred by using rhG-CSF in combination with rhGM-CSF. Although only three infants born to mothers with PIH were studied, our results suggest that therapy with rhG-CSF is likely to be of benefit for such babies.

There have been few reported side effects of rhG-CSF therapy. In contrast, rhGM-CSF has been shown to have effects possibly related to the secondary induction of proinfiammatory cytokines such as tumor necrosis factor- $\alpha$ and IL-6 (IL-6) (23, 24). Monocytes and macrophages are a principle cellular source of tumor necrosis factor- $\alpha$ (25), and increased local production of tumor necrosis factor- $\alpha$ may contribute to neonatal respiratory distress syndrome and its sequelae (26). The fact that monocyte progenitors (CFU-GM) were not increased by rhG-CSF in our study, but were by rhGM-CSF, suggests that rhG-CSF may be safer than rhGM-CSF in preterm neonates.

The lack of correlation between endogenous plasma [G$\mathrm{CSF}$ ] and in vitro response implies that in the clinical situation measurement of plasma [G-CSF] will not usefully predict those babies who will respond to rhG-CSF therapy.

In summary the results of our study indicate that rhG-CSF, but not rhGM-CSF, enhances the rhIL-3-dependent proliferation of neonatal circulating progenitor cells to form greater numbers of CFU-G. rhGM-CSF selectively increases the proportion of CFU-GM but not the overall colony number; and its actions are not synergistic with rhIL-3 or rhG-CSF in the presence of rhIL-3.

Clinical trials in human neonates are warranted to assess the potential use of rhG-CSF for reducing the morbidity and mortality associated with neutropenia, especially when sepsis supervenes.

Acknowledgment. The authors thank Amgen UK for funding laboratory costs.

\section{REFERENCES}

1. Rodwell RL, Faims PHD, Taylor KMCD, Tudehope DI, Gray PH 1993 Hematologic scoring system in early diagnosis of sepsis in neutropenic newborns. Pediatr Infect Dis J 12:372-376

2. Koenig JM, Christensen RD 1989 Incidence, neutrophil kinetics, and natural history of neonatal neutropenia associated with maternal hypertension. $\mathrm{N}$ Engl J Med 321:557-562
3. Lieschke GJ, Burgess AW 1992 Granulocyte colony-stimulating factor and granulocyte-macrophage colony-stimulating factor. N Engl J Med 327:28-35

4. Demetri GD, Griffin JD 1991 Granulocyte colony-stimulating factor and its receptor. Blood 78:2791-2808

5. Ikebuchi K, Clark SC, Ihle JN, Lawrence MS, Ogawa M 1988 Granulocyte colonystimulating factor enhances interleukin 3-dependent proliferation of multipotential hemopoietic progenitors. Proc Natl Acad Sci USA 85:3445-3449

6. Cairo MS, Mauss D, Kommareddy S, Norris K, Van de Ven C, Modanlou H 1990 Prophylactic or simultaneous administration of recombinant human granulocyte colony stimulating factor in the treatment of group B streptococcal sepsis in neonatal rats. Pediatr Res 27:612-616

7. Cairo MS, Plunkett JM, Mauss D, Van de Ven C 1990 Seven-day administration of recombinant human granulocyte colony-stimulating factor to newborn rats: modulation of neonatal neutrophilia, myelopoiesis, and group B streptococcus sepsis. Blood $76: 1788-1794$

8. Gillan E, Christensen RD, Yu S, Ellis R, van de Ven C, Cairo MS 1994 A randomized placebo controlled trial of recombinant human granulocyte colony-stimulating factor in newborn infants with presumed sepsis: significant induction of peripheral and bone marrow neutrophilia. Blood 84:1427-1433

9. Emerson SG, Yu-Chung Y, Clark SC, Long MW 1988 Human recombinant granulocyte-macrophage colony-stimulating factor and interleukin 3 have overlapping but distinct hematopoietic activities. J Clin Invest 82:1282-1287

10. Bot FJ, van Eijk L, Schipper P, Lowenberg B 1989 Human granulocyte-macrophage colony-stimulating factor (GM-CSF) stimulates immature marrow precursors but no CFU-GM, CFU-G, or CFU-M. Exp Hematol 17:292-295

11. Takaue Y, Kawano Y, Reading CL, Watanabe T, Takanori A, Ninomiya T, Shimizu E, Ogura T, Kuroda Y, Yokobayashi A, Nakahata T, Asano S, Ventura G 1990 Effects of recombinant human G-CSF, GM-CSF, IL-3, and IL- $1 \alpha$ on the growth of purified human peripheral blood progenitors. Blood 76:330-335

12. Givner LB, Nagaraj SK 1993 Hyperimmune IgG or recombinant human granulocytemacrophage colony-stimulating factor as adjunctive therapy for group B streptococcal sepsis in newborn rats. J Pediatr 122:774-779

13. Liang DC, Sheau-Wen M, Lin-Chu M, Chung-Chi L 1988 Granulocyte/macrophage colony-forming units from cord blood of premature and full-term neonates: its role in ontogeny of human hemopoiesis. Pediatr Res 24:701-702

14. Christensen RD 1987 Circulating pluripotent hematopoietic progenitor cells in neonates. J Pediatr 110:622-625

15. Cairo MS 1993 Therapeutic implications of dysregulated colony-stimulating factor expression in neonates. Blood 82:2269-2272

16. Manroe BL, Weinberg AG, Rosenfeld CR, Browne R 1979 The neonatal blood count in health and disease. I. Reference values for neutrophilic cells. J Pediatr 95:89-98

17. Miyajima A, Mui ALF, Ogorochi T, Sakamaki K 1993 Receptors for granulocytemacrophage colony-stimulating factor, interleukin-3, and interleukin-5. Blood 82:1960-1974

18. McNiece I, Andrews R, Stewart M, Clark S, Boone T, Quesenberry P 1989 Action of Interleukin-3, G-CSF, and GM-CSF on highly enriched human hematopoietic progenitor cells: synergistic interaction of GM-CSF plus G-CSF. Blood 74:110-114

19. Schmitt RM, Bruyns E, Snodgrass HR 1991 Hematopoietic development of embryonic stem cells in vitro: cytokine and receptor gene expression. Genes Dev 5:728

20. McClanahan T, Dalrymple S, Barkett M, Lee F 1993 Hematopoietic growth factor receptor genes as markers of lineage commitment during in-vitro development of hematopoietic cells. Blood 81:2903

21. Raes M, Alliet P, Gillis P, Zimmermann A, Kortleven J, Magerman K, Peeters V, Rummens J-L 1993 Lymphocyte subpopulations in healthy newborn infants: comparison of cord blood values with values five days after birth. J Pediatr 123:465-467

22. Welte K, Zeidler C, Reiter A, Muller W, Odenwald E, Souza L, Riehm H 1990 Differential effects of granulocyte-macrophage colony-stimulating factor in children with severe congenital neutropenia. Blood 75:1056-1062

23. Stehle B, Weiss C, Ho AD, Hunstein W 1990 Serum levels of tumor necrosis factor $\alpha$ in patients treated with granulocyte-macrophage colony-stimulating factor. Blood 75:1895-1896

24. De Vries EGE, Willemse PHB, Biemsa B, Stern AC, Limburg PC, Vellenga E 1991 Flare-up of rheumatoid arthritis during GM-CSF treatment after chemotherapy. Lancet 338:517-518

25. Kelker HC, Oppenheim JD, Stone-Wolff D, Henriksen-DeStefano D, Aggrawal BB Stevenson HC, Vilcek J 1985 Characterization of human tumor necrosis factor produced by peripheral blood monocytes and its separation from lymphotoxin. Int $\mathbf{J}$ Cancer 36:69-73

26. Murch SH, MacDonald TT, Wood CBS, Costeloe KL 1992 Tumour necrosis factor in the bronchoalveolar secretions of infants with the respiratory distress syndrome and the effect of dexamethasone treatment. Thorax 47:44-47 